\title{
Video Article \\ Proprioception and Tension Receptors in Crab Limbs: Student Laboratory Exercises
}

\author{
Zana R. Majeed ${ }^{1,2}$, Josh Titlow ${ }^{1,2}$, H. Bernard Hartman ${ }^{3}$, Robin Cooper ${ }^{1,2}$ \\ ${ }^{1}$ Department of Biology, University of Kentucky \\ ${ }^{2}$ Center of Muscle Biology, University of Kentucky \\ ${ }^{3}$ Oregon Institute of Marine Biology, University of Oregon
}

Correspondence to: Robin Cooper at rlcoop1@uky.edu

URL: https://www.jove.com/video/51050

DOI: doi:10.3791/51050

Keywords: Neuroscience, Issue 80, Crustacean, joint, Muscle, sensory, teaching, educational, neuroscience

Date Published: 10/24/2013

Citation: Majeed, Z.R., Titlow, J., Hartman, H.B., Cooper, R. Proprioception and Tension Receptors in Crab Limbs: Student Laboratory Exercises. J. Vis. Exp. (80), e51050, doi:10.3791/51050 (2013).

\section{Abstract}

The primary purpose of these procedures is to demonstrate for teaching and research purposes how to record the activity of living primary sensory neurons responsible for proprioception as they are detecting joint position and movement, and muscle tension. Electrical activity from crustacean proprioceptors and tension receptors is recorded by basic neurophysiological instrumentation, and a transducer is used to simultaneously measure force that is generated by stimulating a motor nerve. In addition, we demonstrate how to stain the neurons for a quick assessment of their anatomical arrangement or for permanent fixation. Staining reveals anatomical organization that is representative of chordotonal organs in most crustaceans. Comparing the tension nerve responses to the proprioceptive responses is an effective teaching tool in determining how these sensory neurons are defined functionally and how the anatomy is correlated to the function. Three staining techniques are presented allowing researchers and instructors to choose a method that is ideal for their laboratory.

\section{Video Link}

The video component of this article can be found at https://www.jove.com/video/51050/

\section{Introduction}

Proprioception is the sensation of limb position and movement that enables coordinated motor behavior. Proprioceptors consist of position (static) and movement (kinesthetic) receptors. In insects and crustaceans, chordotonal organs are the structures that provide that information to the CNS ${ }^{1}$. Not all chordotonal organs span a joint but they can still monitor joint movements due to their attachment on the apodemes (tendon like structures) which span the joint and move in association with the skeletal muscle and joint articulation. Crab legs have six joints, each having one or two chordotonal organs ${ }^{2}$. Typically a chordotonal organ has 60-100 or more sensory neurons embedded within an elastic strand, neurons that signal static joint position, direction and speed of movement ${ }^{3-6}$. The input from chordotonal organs at each joint and leg is then centrally processed allowing coordinated movements by the animal.

The forces that leg muscles produce during isometric and isotonic contractions are detected by tension receptors associated with muscle fibers and their attachments to apodemes7-9. In the crustacean walking leg protocols that follow we present methodology for recordings from primary sensory neurons that monitor proprioception and the neurons that respond to forces generated by muscle fibers. A technique for activating leg movements and quantifying force generation is also presented, as well as anatomical techniques that can be used to characterize the arrangement of these peripheral nervous system structures.

The procedures demonstrated below enable structural and functional analysis of the neurons that innervate both types of receptors relative to their location on a chordotonal elastic strand and apodeme. To illustrate, we use the propodite-dactylopodite (PD) chordotonal organ, the organ that spans the distal most segment of the crab leg ${ }^{3}$. Though detailed electrophysiological studies began in the 1930s and are still being carried out today, some aspects have become known about the segmental connections of proprioceptors in the various joints and their roles in coordinated control of muscles10-16. Establishing the structure-function relationship between the proprioceptive organs, muscles and the nervous system will further help define these roles. For instance, labeling the somata and distal endings of tension neurons inserted into the apodeme will reveal their location relative to muscle fibers ${ }^{8,17-21}$.

We present three staining techniques for crustacean legs that can be used in research or academic laboratories. Methylene blue staining provides suitable contrast for muscles and nerves and is recommended as a simple technique for students to learn anatomy. Labs that have fluorescence microscopy setups can accomplish more selective neuronal staining by briefly exposing the nerves to the vital dye 4-di-2-ASP. The third alternative is $\mathrm{CoCl}_{2}$ backfill, which stains and fixes the neurons, and does not require fluorescence imaging. Though it is labor and time intensive, this staining process gives high contrast and specificity for the nerves that are filled. Together these techniques can be used for comparing various chordotonal organs, not only within a limb or between limbs, but also among other crustacean and insect species ${ }^{20-22}$. Blue crabs (C. sapidus) used in physiological recordings and for anatomical staining are readily available all around the Southern and Southeastern 
border of the United States. This species serves as a representative of the chordotonal and tension nerve arrangements found in most crabs. Laboratories on the west coast will prefer to use the much larger Dungeness crab (Cancer magister) for these experiments.

\section{Protocol}

\section{Dissection and Recording Electrical Activity from the Propodite-dactylopodite (PD) Nerve}

1. Hold the crab across the carapace from behind, and avoiding the claws, pinch the proximal part of the meropodite with forceps. The leg will autotomize to prevent the animal from bleeding to death. Use caution when handling blue crabs as they are rather aggressive and very fast.

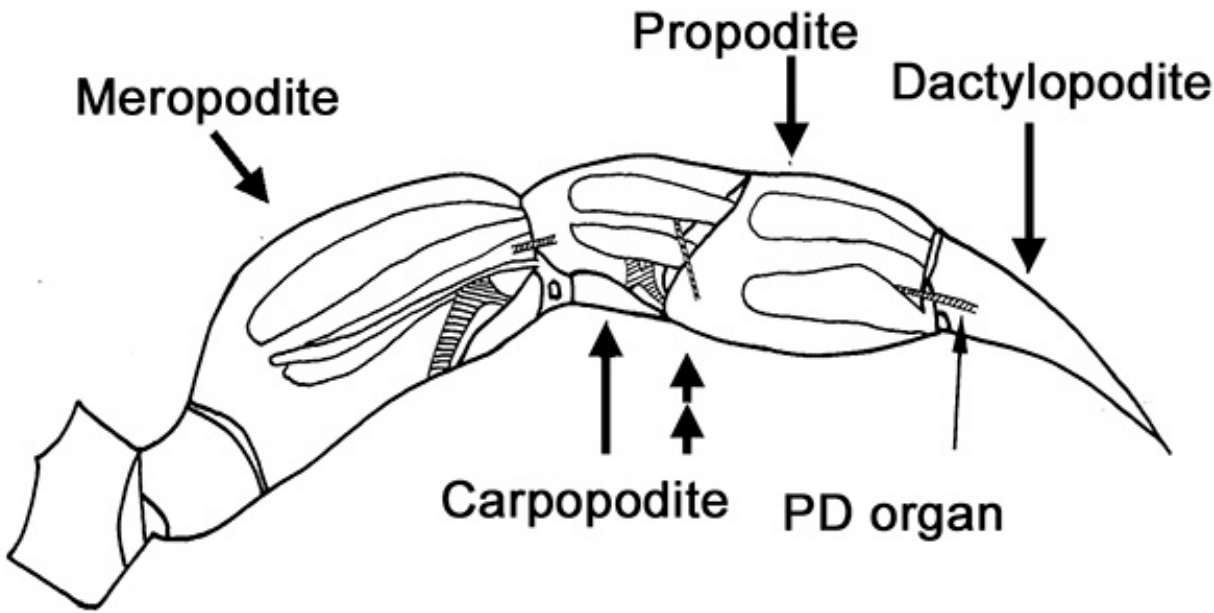

Figure 1. First walking leg of a crab. The anatomical location of chordotonal organs (hatched regions) are superimposed on this schematic. The double arrow head indicates where to transect the leg for the PD nerve experiments. Click here to view larger image.

2. Make a cut between the propodite and carpodite. Discard the carpopodite and the attached meropodite (Figure 1).

3. Cut a large window in the cuticle on the pigmented (lateral) side of the propodite with a scalpel with a \#11 blade (Figure 2 and 3 ). Note: Do not cut deeply.

4. Remove the cuticle layer by sliding the scalpel blade beneath and parallel to the cuticle. This severs the muscle fibers attached to the cuticle.

5. Using the same technique cut a smaller window on the pigmentless (medial) side of the propodite, but leave the condyle (the socket joint or hinge between segments) attachment intact.

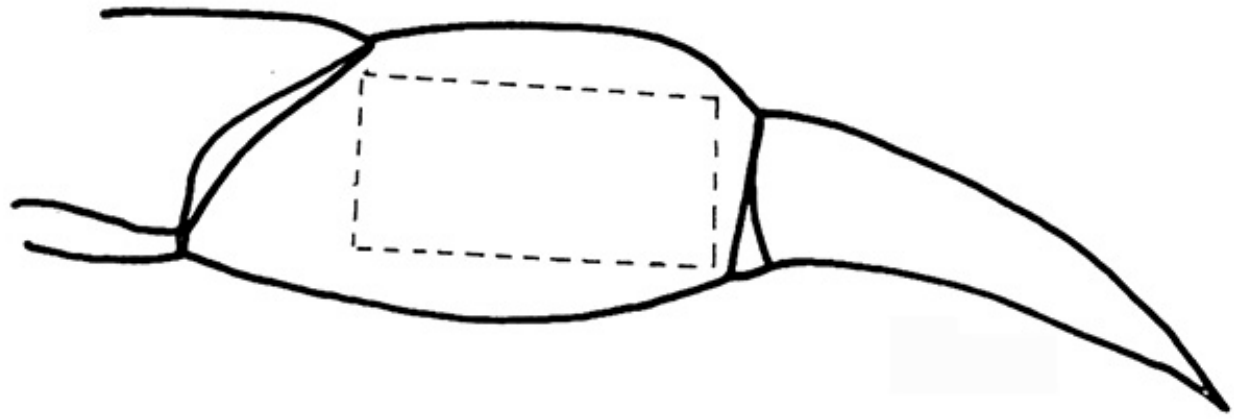

Figure 2. Cut along the dotted line on the propodite. Click here to view larger image. 


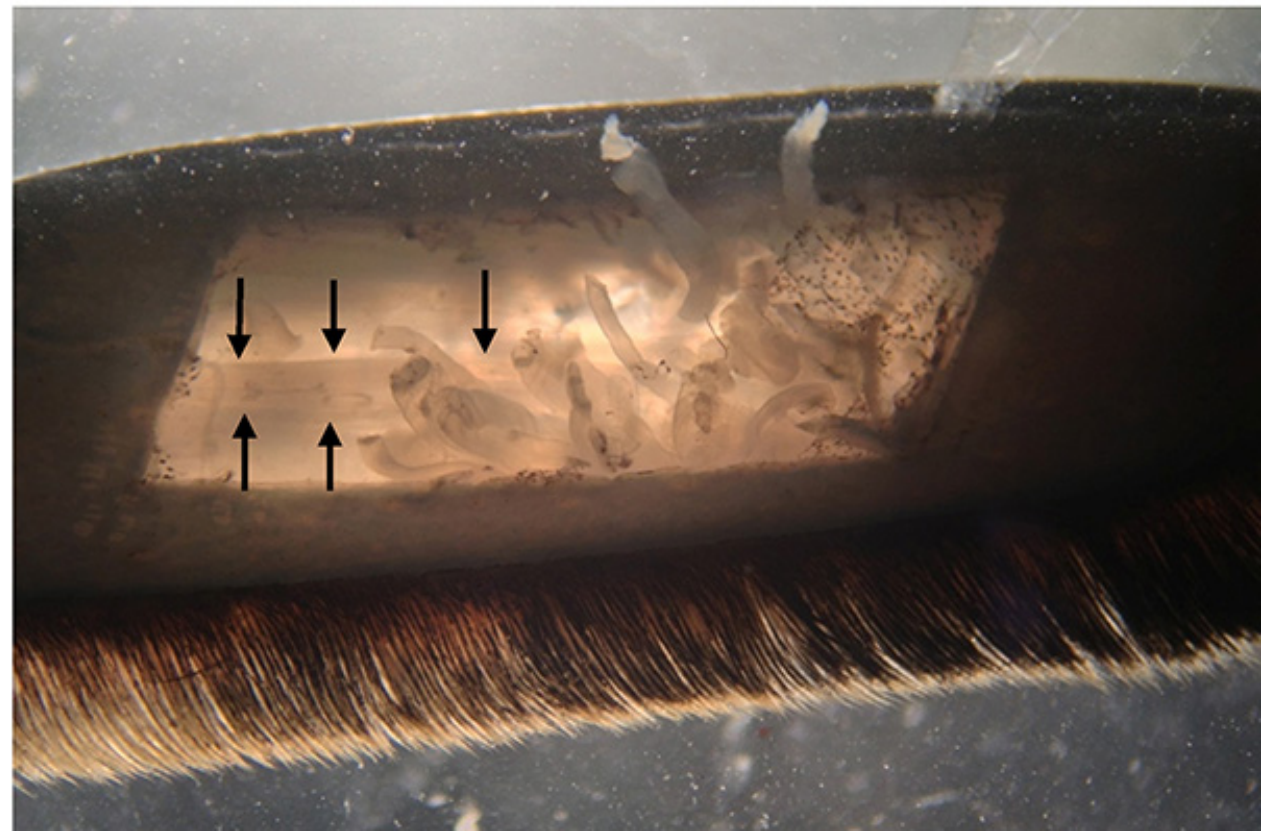

Figure 3. Expose the nerve in the window (the arrows outline the nerve bundle). Click here to view larger image.

6. Prepare a Sylgard-lined dish containing crab saline to pin the preparation down. Note: See Table 1 for species specific saline recipes.

7. Locate the PD organ by carefully probing with the fire-polished glass needles. The elastic strand spanning the joint has a silver appearance.

8. Remove muscle fibers that obscure your view of the organ from both sides of the tendon. Be very careful not to injure the PD organ or its nerve.

9. Once this has been accomplished, firmly reattach the preparation to the dish with the pigment side (lateral) facing up (Figure 4).

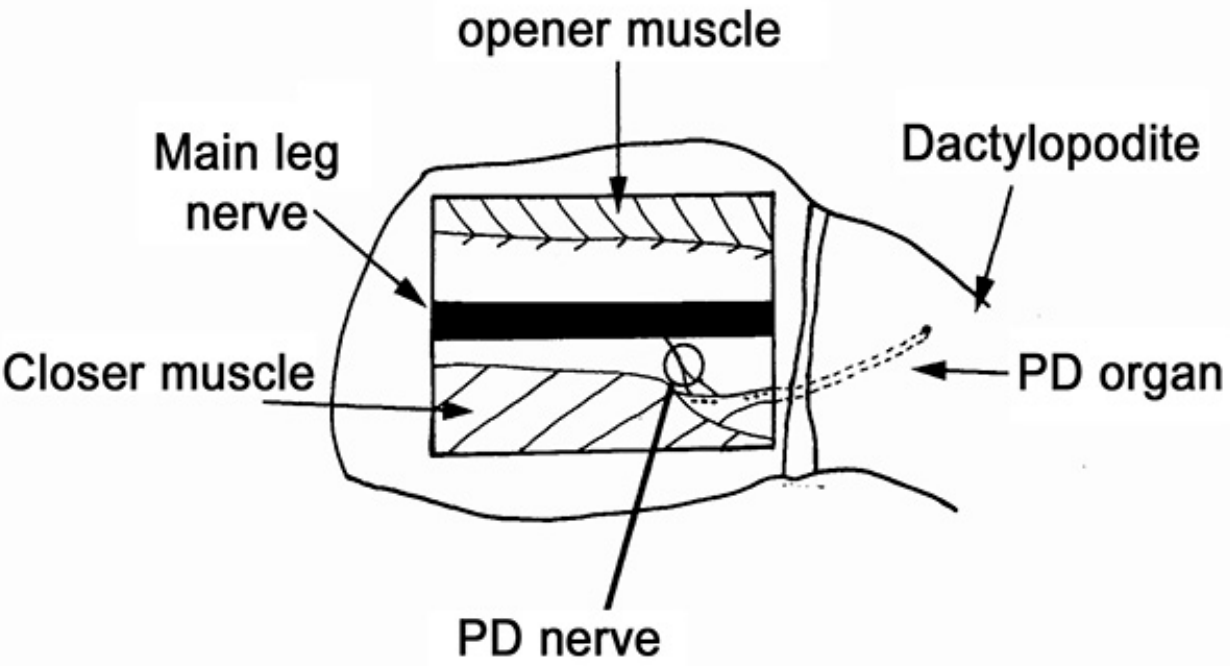

Figure 4. Exposed PD organ and nerve. Click here to view larger image.

10. Follow the PD organ nerve in the propodite as far proximally as possible in order to free-up a long length of nerve $(1.5 \mathrm{~cm})$ for recording purposes. This is best done while the PD nerve is still attached to the main leg nerve.

11. After separating the PD nerve from the main leg nerve with the aid of glass needles, sever the PD nerve proximally with the iris scissors. Note: Do not stretch or pull on the nerve during the dissection.

12. Move the dactylopodite to an extended and fully flexed position. Take note about where the extreme flexion and extension positions are and a half-way point for later use.

13. Place a ground wire inside the saline bath.

14. Turn on the electrophysiology recording hardware/software. Note: Our setup has been described previously ${ }^{23}$

15. Position the microscope so that it is overlooking the microscope stage. Once the prep dish is placed on the stage, you will need to adjust the position of the high intensity illuminator beam to best visualize the preparation.

16. Position the micromanipulator so the attached suction electrode assembly will have easy access to the saline bath and preparation. The suction electrode is constructed as shown in an online video ${ }^{24}$.

17. To detect neural activity, draw the cut end of the PD nerve into the suction electrode.

18. Move the dactyl throughout extended and flexed positions for several cycles with the aid of a glass probe or wooden dowel.

19. Next observe activity when the dactyl is pinned in the extended, flexed, and mid positions. 


\section{Recording Electrical Activity from the Tension Nerve while Monitoring Force Generation}

1. Determine the lateral and medial side of the leg. The medial side has a soft texture that can be felt by pinching gently in the meropodite region with a fingernail.

2. Place this soft cuticle side up in the dish. The excitor motor nerve that innervates the opener muscle also innervates the stretcher muscle in the carpopodite.

3. In order to stimulate the opener muscle the stretcher motor nerve in the carpodite region is isolated and stimulated with a suction electrode. The proximal part of the leg is removed by transecting the meropodite with scissors.

4. Remove a section of the cuticle in the carpus region on the inner side (medial side, Figure 5A).

5. Cut the apodeme of the bender muscle and remove the muscle carefully as not to pull the main leg nerve out of the leg cavity (Figure 5B, C note the arrows where to bender apodeme is separated). The main leg nerve and a branch to the stretcher muscle can then be observed (Figure 5D).

6. Find the nerve branching from the main nerve bundle to the stretcher muscle (Figure 5E, at arrow). This can be cut close to the muscle and pulled into a suction electrode to stimulate (Figures $\mathbf{5 F}$ and $\mathbf{G}$, arrow depicts the branch).

7. Tease out a section of the nerve that projects towards the opener without pinching the nerve. Transect the stretcher/opener motor nerve.

8. Pull the motor nerve into the suction electrode and then stimulate it.

9. To expose the opener muscle and tension nerve remove the closer muscle and the ventral region of the propodite. Cut off the closer muscle with a scalpel with a \#11 blade in the propodite (Figure 6). Note: Do not cut deeply in the proximal region because it might damage the opener motor nerve.
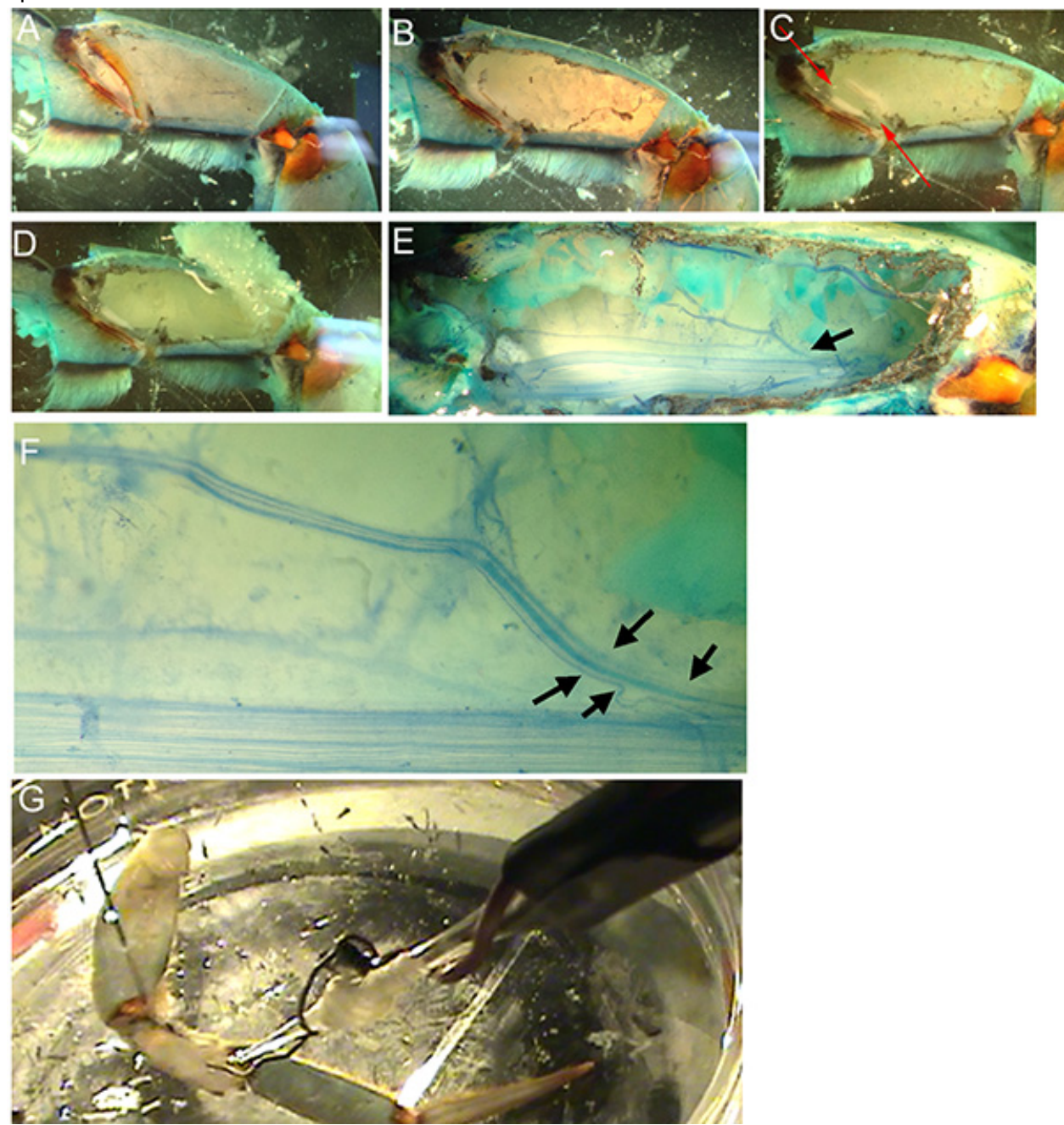

Figure 5. Dissection steps for exposing the motor neuron for stimulating the opener muscle. Click here to view larger image. 


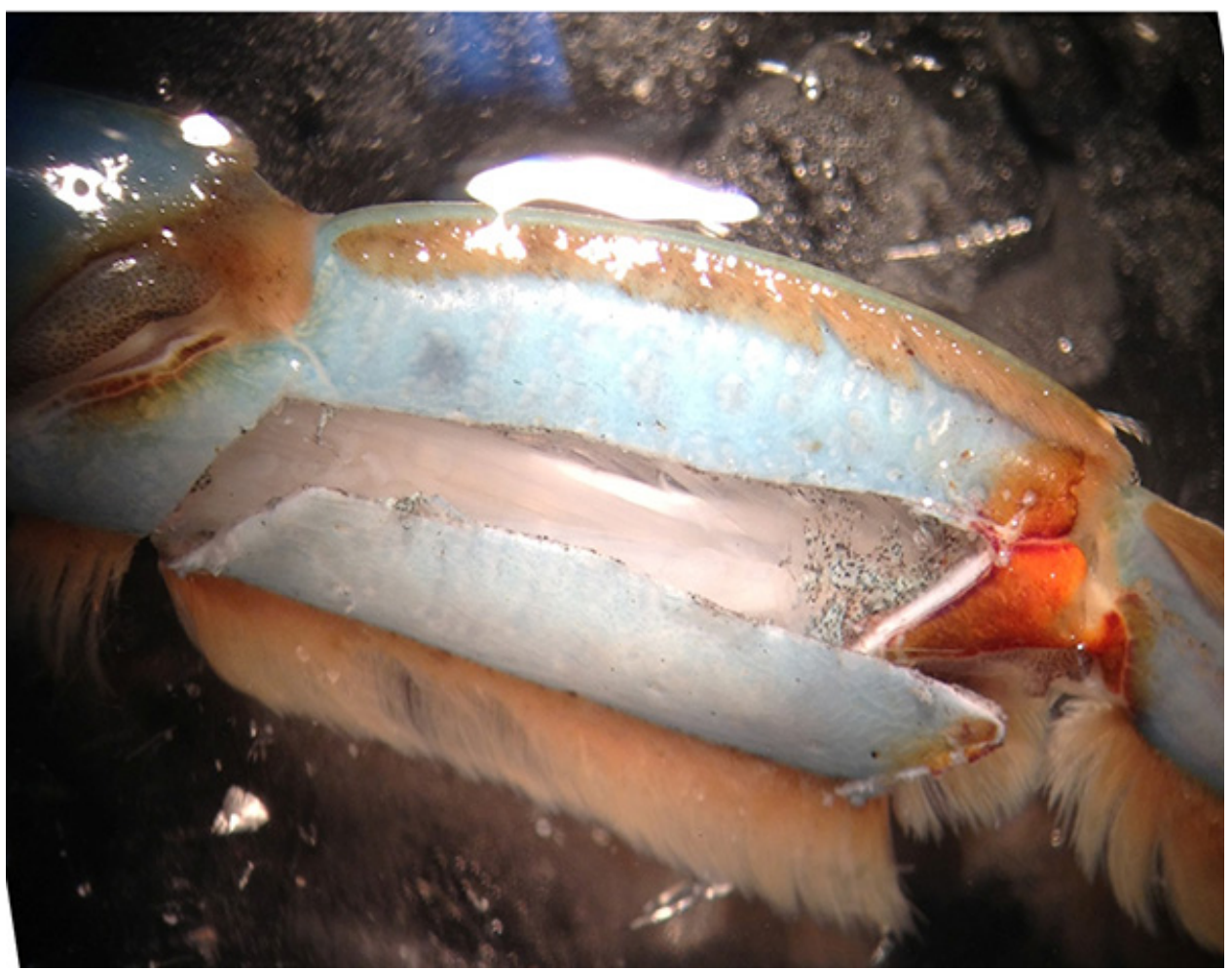

Figure 6. Cut the cuticle on the ventral half of the propodite to expose the closer muscle so it can be removed. Click here to view larger image.

10. Exchange the saline with fresh cooled saline throughout the dissection process to keep the neurons alive. For further dissection, place the preparation dish under a dissecting microscope and use fiber-optic illumination.

11. Carefully cut the closer tendon from its attachment to the dactyl using sharp-pointed medium-size scissors.

12. Be very careful not to disturb the branches to the opener muscle from the main leg nerve which should be clearly visible.

13. Remove and discard the closer muscle and tendon.

14. Make a hole in the dactyl with a dissection pin. This hole will be used later to hook the metal pin on the tension (force) transducer, but it is necessary to make it at this stage of the procedure.

15. Locate the nerve branch that projects to the opener muscle and apodeme in the distal region of the opener muscle. Carefully probe the nerve with the fire-polished glass tool.

16. Observe the tension nerve that arises from the distal end of the apodeme and proceeds to the motor nerve bundle.

17. To detect neural activity, fill a suction electrode with crab saline and draw the cut end of the opener tension nerve into the electrode. Ensure that the suction electrode fits tightly on the nerve.

18. Examine for the neural correlate of passive tension on the opener apodeme. While recording electrical activity from the tension nerve, rotate the dactyl rapidly into an extended joint (i.e. stretching the opener muscle).

19. Next, test active force development in relation to stimulation frequency.

20. Firmly attach a metal hook so that the tip of the hook goes through a small hole in the dactyl.

21. Attach the other end of the metal hook to the force transducer. Note: Make sure the transducer is at a $90^{\circ}$ angle each time so that the pin is perpendicular to the transducer for maximal detection of the force generated.

22. Pull the hook and dactyl so that it is at about a $45^{\circ}$ angle of the opener joint.

23. Now stimulate the motor nerve at $100 \mathrm{~Hz}$ for $250 \mathrm{msec}$ and measure the force as well as the firing frequency of the tension nerve.

24. Place the joint into a fully extended position so that the opener muscle fibers are flaccid.

25. Stimulate the motor nerve at $100 \mathrm{~Hz}$ for $250 \mathrm{msec}$ and measure the force as well as the firing frequency of the tension nerve.

26. Bend/flex the joint so that it is fully flexed $\left(\sim 90^{\circ}\right)$. In this position the muscle fibers of the opener are fully stretched. There may be some force measured by the transducer due to this passive stretch of the muscle.

27. Stimulate the motor nerve at $100 \mathrm{~Hz}$ for $250 \mathrm{msec}$ and measure the force as well as the firing frequency of the tension nerve.

28. After measuring a force, proceed in a series of various frequencies: $20,40,60,80$, and $100 \mathrm{~Hz}$ for $8-10$ sec in each joint position.

29. Measure the response with a quick tension release. Arrange the preparation so that the hook on the force transducer can easily be pushed out of the hole in the dactyl.

30. Bend/flex the joint so that it is fully flexed $\left(\sim 90^{\circ}\right)$. Now stimulate the motor nerve at $100 \mathrm{~Hz}$ with a continuous stimulation of $5 \mathrm{sec}$.

31. After the first second or less, as tension has built up on the opener muscle, push the pin out of the hole in the dactyl.

32. Examine the tension nerve recording before and after release of the pin holding the dactyl.

33. Modulatory effects of neuroactive substances such as octopamine, serotonin, and proctolin, which alter the output of the tension neurons, can be determined by adding these molecules to the bathing media over the exposed opener muscle and repeating the experiments.

34. Use a pipette and drip 1-2 $\mathrm{ml}$ over the preparation. 


\section{Staining Peripheral Nervous System Structures in Crustacean Walking Legs}

1. Methylene blue technique

1. Dilute one part methylene blue chloride stock solution $(0.25 \%)$ with two parts of distilled water.

2. Add this mixture to five parts of buffered saline. Thoroughly irrigate the area of interest.

3. Dissect a leg according to the protocol in section 1. Incubate the preparation in the methylene blue solution at $12-13^{\circ} \mathrm{C}$.

4. Examine the preparation every $10-15$ min with the dissecting microscope using low intensity illumination to follow the progress of the staining. In some cases staining will be completed in an hour, in others it may take overnight.

\section{4-di-2-ASP technique}

1. Fluorescent dyes can be used to back-fill the PD neuron or directly stain the preparation from the bath. However a suitable microscope with abilities to view the fluorescent stain is required.

2. Dissect a leg according to a protocol in section 1.

3. Incubate the preparation in a $10 \mu \mathrm{M}$ concentration of 4-Di-2-ASP solution and leave the preparation in the refrigerator for 15 min. Use just enough solution to cover the preparation.

4. Photograph the preparations quickly and avoid over exposure to the mercury light. This fluorescent dye fades away relatively quickly.

\section{Cobalt chloride technique}

1. Expose the PD nerve according to the protocol in section 1 and keep it immersed in cold saline.

2. Make a petroleum jelly well to hold the $\mathrm{CoCl}_{2}$. If any $\mathrm{CoCl}_{2}$ spills into the saline bath the entire preparation will stain black, and the preparation should be discarded.

3. Slip a small cut of a polystyrene sheet, to make a plastic platform, and pin it in such a manner that it will not float away or become immersed in the saline bath (Figure 7).

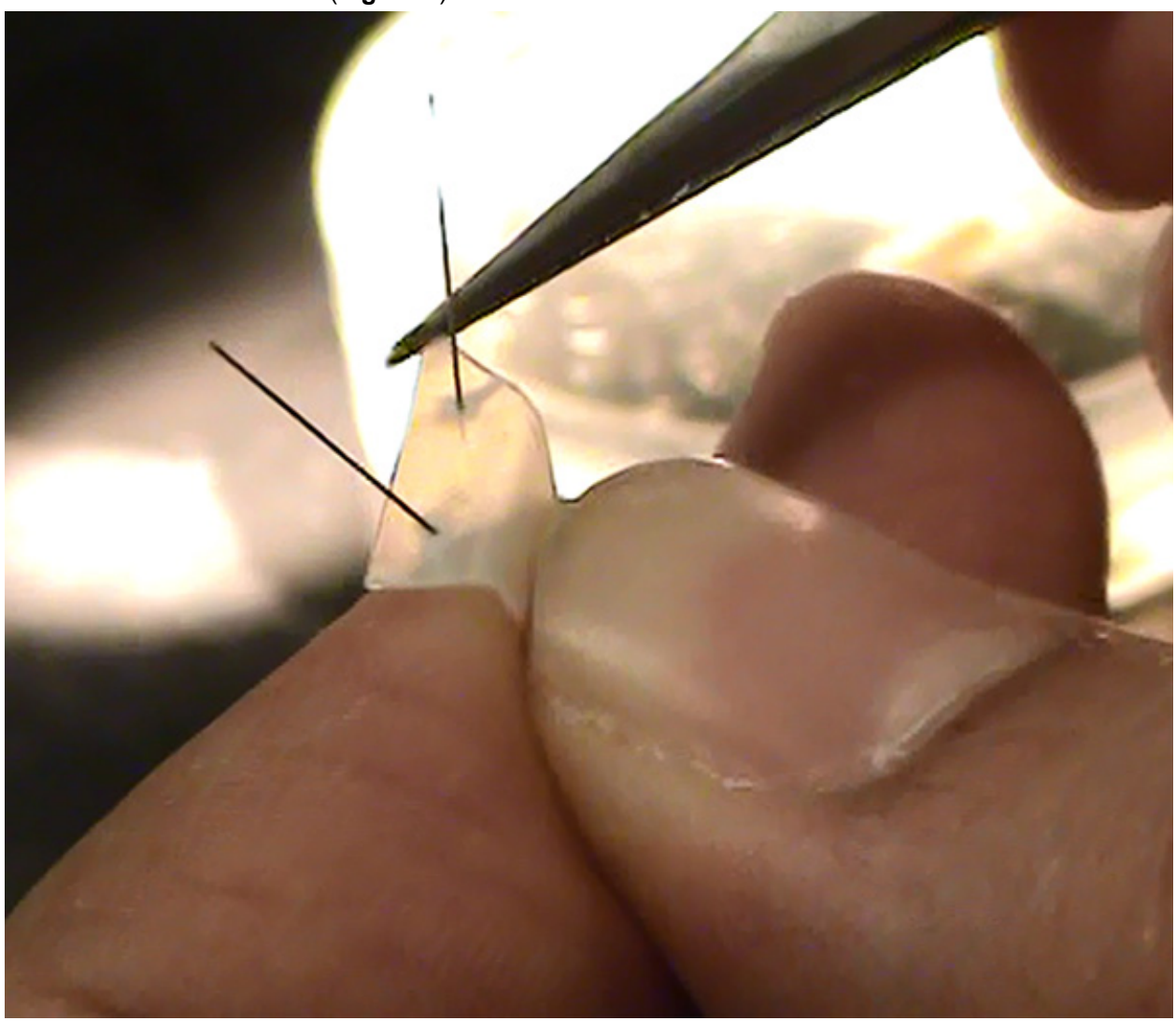

Figure 7. Polystyrene sheet with pins to hold in place in dish. Click here to view larger image.

4. Eject petroleum jelly from a fine hypodermic needle fastened to a disposable syringe, then make a barrier (a circle might work well), which should be about 1-1.5 mm high except for a shallow " $\mathrm{V}$ " at midpoint where the nerve will be draped across, on top of the slip of polystyrene.

5. Make a small puddle of saline on either side of the barrier near the "V". Taking care not to stretch or pinch the nerve, lift the nerve carefully from the dish and place it in the saline puddle in the petroleum jelly well.

6. Work quickly so that the section of nerve does not dry out, carefully eject petroleum jelly to cover the exposed nerve. Now test the barrier with saline and make sure it is not leaking.

7. Blot away saline on the inside of the barrier and see if it fills up when the bath saline is high around the wall of petroleum jelly to be sure that the two sides are isolated from one another (Figure 8). 


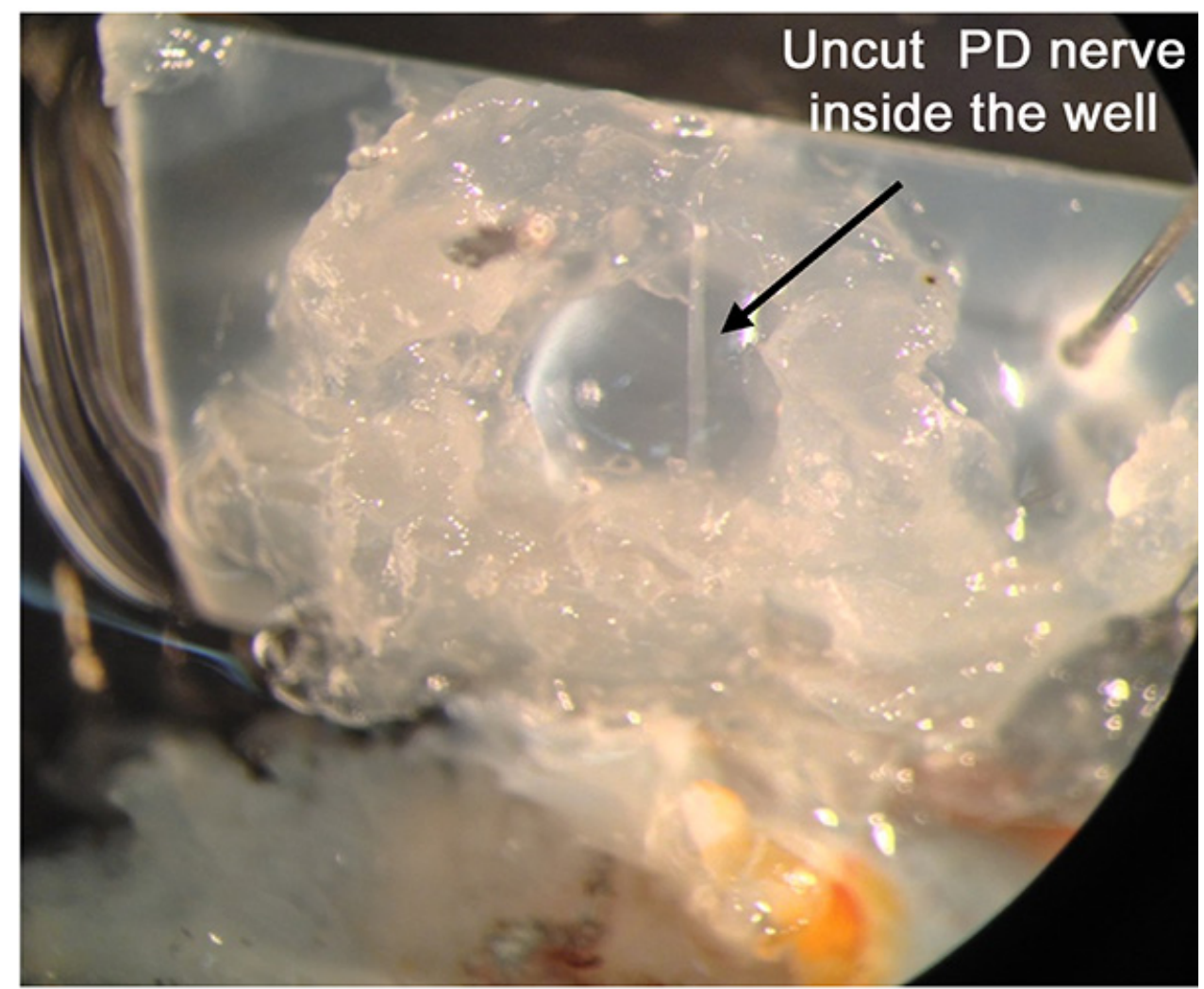

Figure 8. Petroleum jelly well with saline and PD nerve spanning the well. The PD nerve has not been cut yet. Click here to view larger image.

8. Wick away the saline in the well using a piece of tissue paper. Avoid letting the paper wrap up the nerve.

9. Make a new puddle using a few small drops of distilled water, and then cut the nerve end. Be very careful not to pull the nerve through the barrier when making the cut. The osmotic shock of the distilled water will "balloon" the axons.

10. Within $30 \mathrm{sec}$ add a small drop of $\mathrm{CoCl}_{2}$ to the water, soak up this solution, and then add enough $\mathrm{CoCl}_{2}$ to form a puddle over this shortened section of nerve (Figure 9). Preparations are best kept refrigerated at $13^{\circ} \mathrm{C}$ for $12-24 \mathrm{hr}$. 


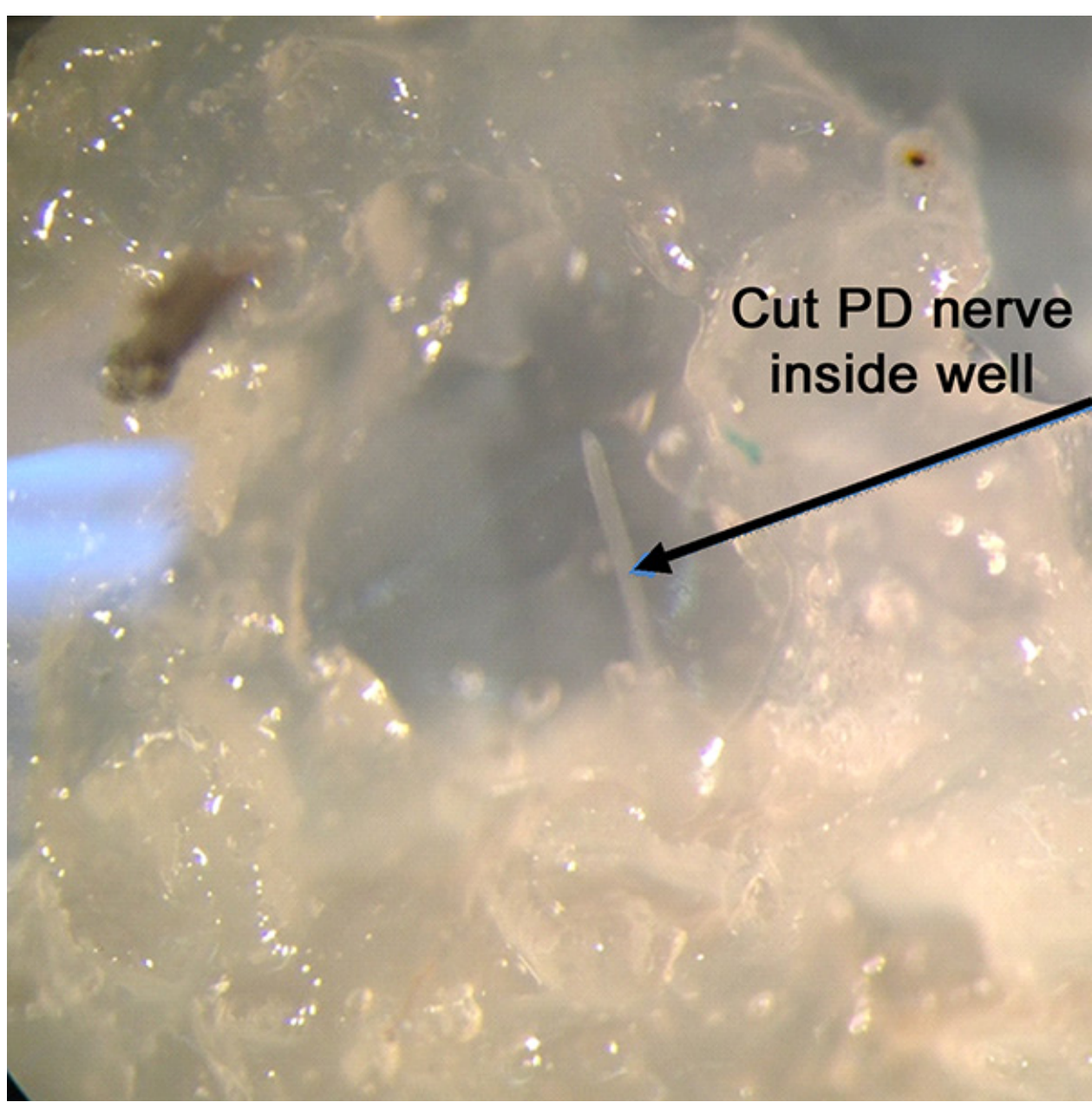

Figure 9. The cut PD nerve being exposed to $\mathrm{CoCl}_{2}$. The cut nerve swells up in the presence of water that facilitates and accelerates the movement of dye molecules through the axons into the neuron cell bodies. Click here to view larger image.

11. Remove the humidifying puddles. Blot away the cobalt solution using a tissue and wash away the remnants of cobalt with several changes of saline.

12. Transfer the isolated preparation to a small glass Petri dish containing about $10 \mathrm{ml}$ of crab saline. The neurons are washed and the following steps are performed in situ. Good metal tools are not to be used to handle the preparation after this step (you should use specific tools that are not to be used at a later time for physiology).

13. Add 1-2 drops of ammonium sulfide $\left(\mathrm{NH}_{4}\right)_{2} \mathrm{~S}$ to the saline. Cap the $\left(\mathrm{NH}_{4}\right)_{2} \mathrm{~S}$ bottle tightly and place back into the hood. Observe the reaction in the preparation under a dissecting microscope

14. Within 1-2 min, cobalt-filled neurons and their processes should begin to appear because they will stain black.

15. After $5-10 \mathrm{~min}$, replace the development solution with fresh saline.

16. Make certain that the development solution you have poured into the sink drain is followed by running tap water for a few minutes or in a waste bottle with a lid.

17. Pour out the saline and fix the nerve preparation for about 15 min with two changes of Bouin's solution fixative. For larger tissues like the opener muscle (to stain tension neurons), increase the duration of fixation to $30 \mathrm{~min}$.

18. Dehydrate in a series of ascending order of ethanol concentration beginning at $70 \%$ (i.e. $70 \%, 80 \%, 90 \%, 100 \%$ ). About 10 min at each concentration is sufficient for small tissues.

19. After about $10-15$ min in two changes of $100 \%$ ethanol, clear the tissue by replacing ethanol with $100 \%$ methyl salicylate. The preparation will stay in this solution permanently for repeated viewing. With time the filled cells will become more apparent because the surrounding tissue will become clearer. Intensification methods can be used to help prevent fading over time ${ }^{25}$.

20. Use the same process to fill the tension nerve with $\mathrm{CoCl}_{2}$. However, change ethanol solution multiple times in each ethanol dehydration step and incubate the preparation inside alcohol for about $20 \mathrm{~min}$ for each step to thoroughly dehydrate the muscles and allow them to clear well.

\section{Representative Results}

When the PD organ is stretched by fully extending the joint, activity in the PD nerve is robust during the movement as shown for the first second in Figure 10. Some activity remains while it is held still in the open position. This activity is from the static position sensitive neurons (second half 
of the recording shown in Figure 10). Movement evokes a response during displacement, and the firing is mostly present during the stretching of the chordotonal strand (Figure 11).

Further analysis of the spikes can be readily approached by sorting the relative amplitudes. This is an approach to demonstrate different populations of sensory neurons being recruited for positions or types of movements ${ }^{5}$. Typical amplitudes range from $0.25-1.5 \mathrm{mV}$, but these values are dependent on the resistance (i.e. tightness) of the suction electrode seal. Frequency of spikes in the various size ranges can also be graphically represented for analysis.

Forces generated by the opener muscle with respect to the stimulation frequency can be compared by superimposing the respective voltagetime traces on top of each other (Figures 13A and B). This can also be performed for each joint position at each given stimulation frequency. Activity of the tension nerve can then be correlated with the amount of relative force generated at each stimulation frequency, and for each joint position. As in the PD nerve, a variety of spike amplitudes are seen in response to contraction of the opener muscle (Figure 13C).

Anatomical arrangement of neurons in the walking leg is clearly observed with methylene blue staining (Figure 14). Note the elastic chordotonal strand and tension neuron that is close to the apodeme. Several somata with different diameters and specific locations are also visible in this figure. The entire course of the tension nerve and stretcher motor nerve are shown in Figure 15. Individual neurons of the PD nerve are shown with higher contrast using 4-Di-2-ASP (Figure 16) and $\mathrm{CoCl}_{2}$ (Figure 17) backfill techniques. At high magnification the sensory endings can be seen inside of the supportive scolopales (Figures 16B) $)^{21,22,26}$.

\section{Static}

\section{Movement}
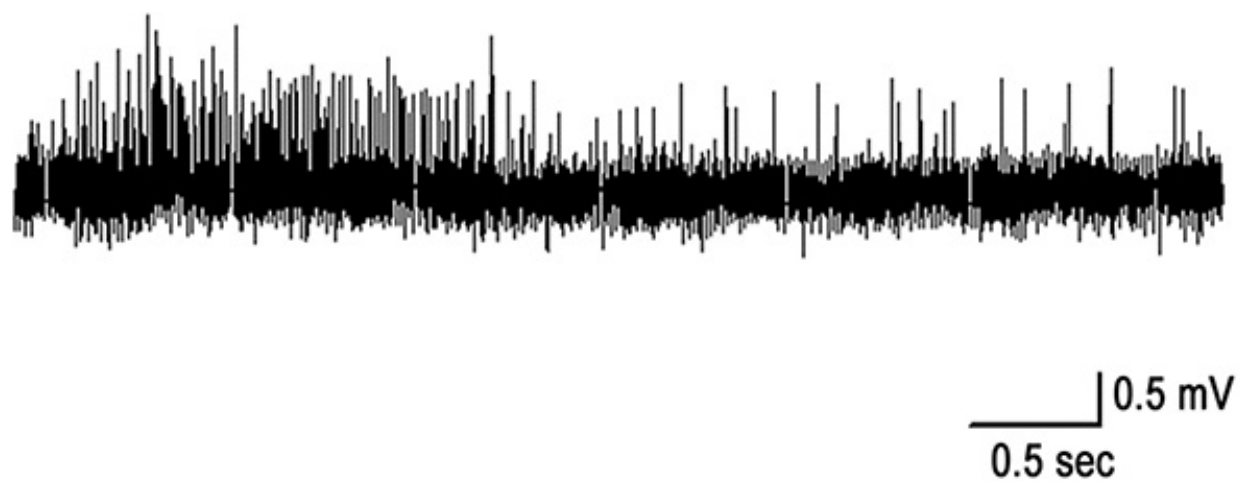

Figure 10. Move and hold at $0^{\circ}$. The dynamic neurons are robust in firing during the movement and spikes from static sensitive neurons are present while the joint is held open. Click here to view larger image.
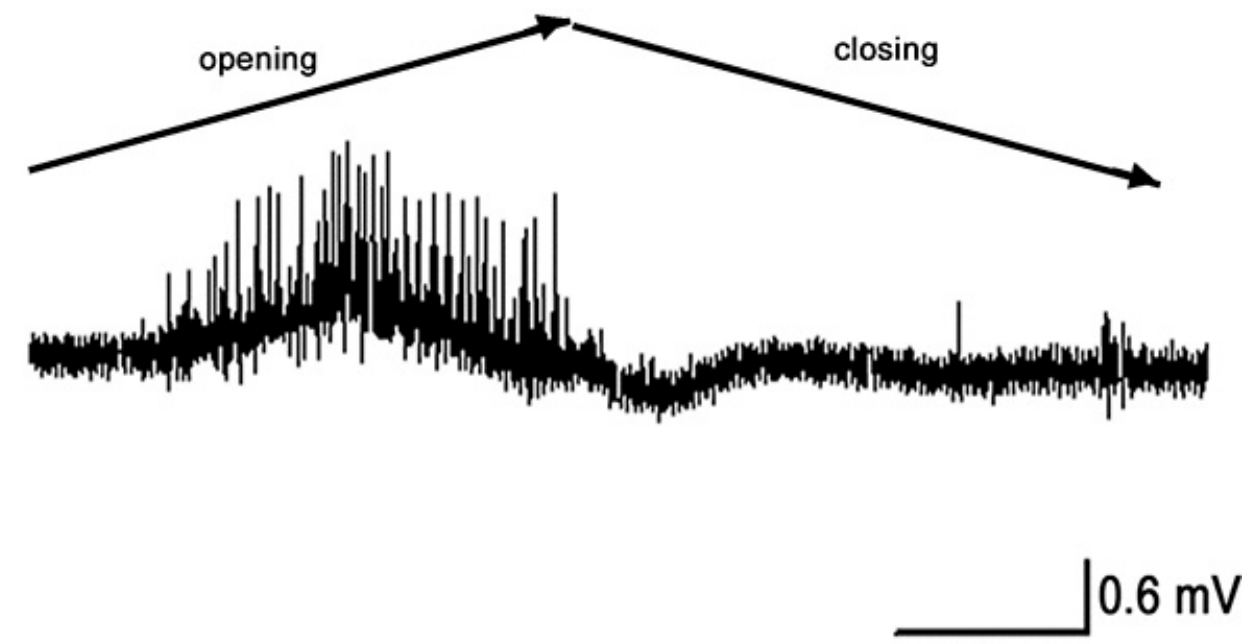

\section{$0.5 \mathrm{sec}$}

Figure 11. Rapid open and closing from fully flexed to extended $\left(\mathbf{9 0}-0^{\circ}\right)$ position. Click here to view larger image. 


\section{Movement}

\section{Static}
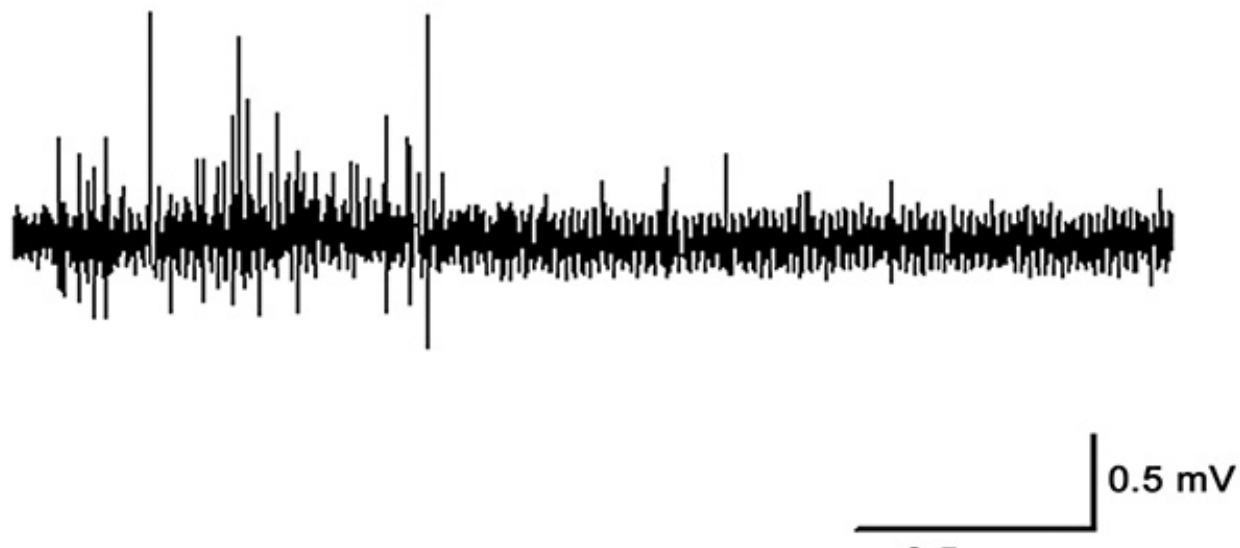

$0.5 \mathrm{sec}$

Figure 12. Extracellular spikes recorded from the PD nerve. The joint is fully extended and then quickly moved to a $1 / 2$ flexed position and then held still. Notice the activity during the movement and decreased activity when static. Click here to view larger image. 

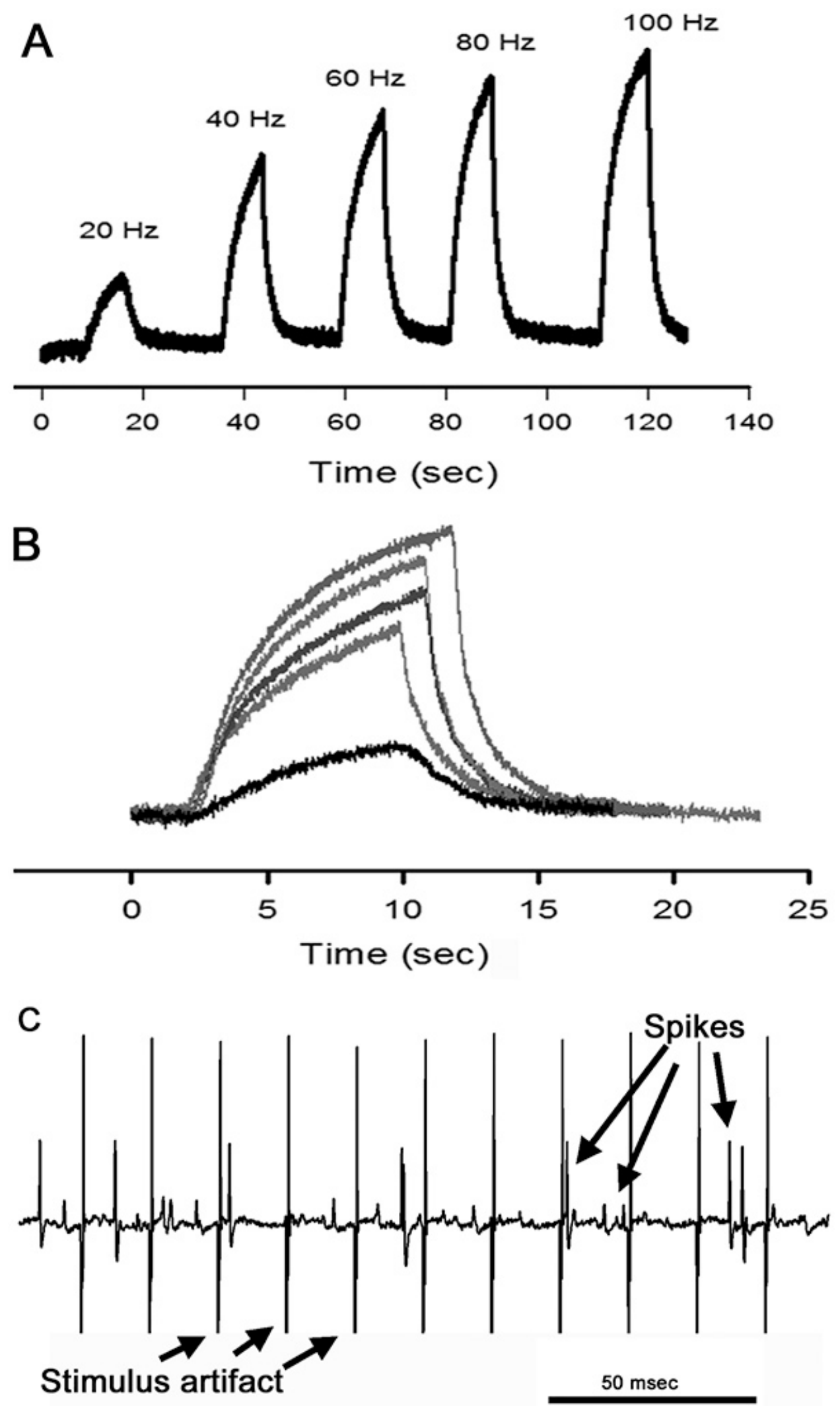

Figure 13. The relative forces that are developed with the joint fully flexed and stimulated at the various frequencies. (A) Voltage-time traces from the force transducer are shown with each stimulation frequency. (B) The traces in panel A are superimposed in different colors for ease in comparison. (C) Voltage-time traces of electrical activity recorded from the tension nerve when the motor nerve was stimulated at $80 \mathrm{~Hz}$. Note the regular pattern of the stimulus artifacts as compared to the neural activity. Also, note the various amplitudes of the neural responses. Click here to view larger image. 


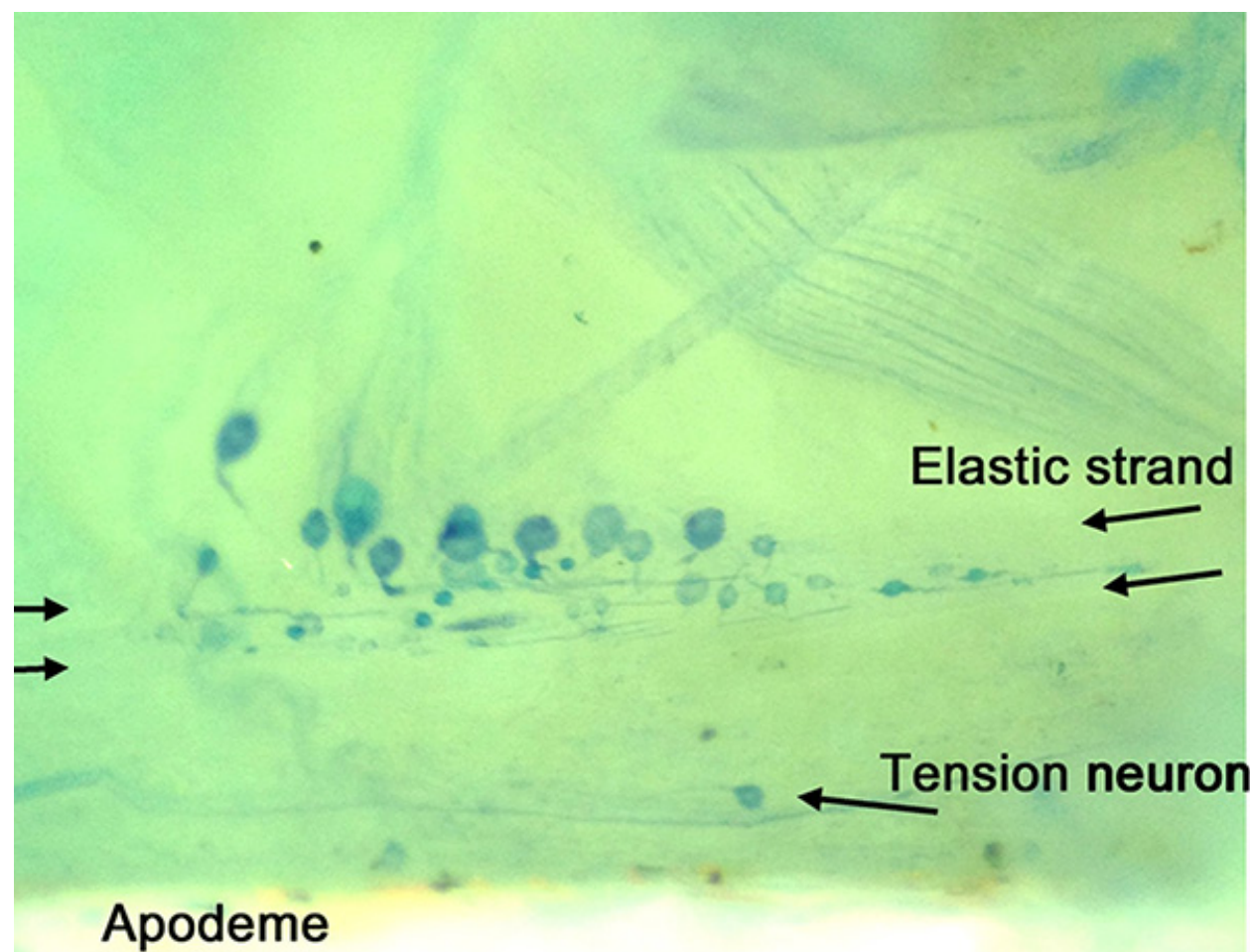

Figure 14. Methylene blue stain of the walking leg preparation. Individual somas are shown with their sensory endings projecting into the elastic strand. Close to the apodeme a tension neuron is shown. Click here to view larger image.

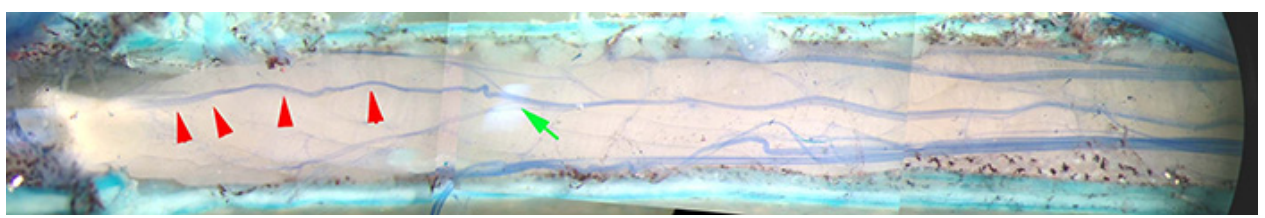

Figure 15. The tension nerve arising from distal end (red arrows) and joining the motor nerve (green arrow). Click here to view larger image. 


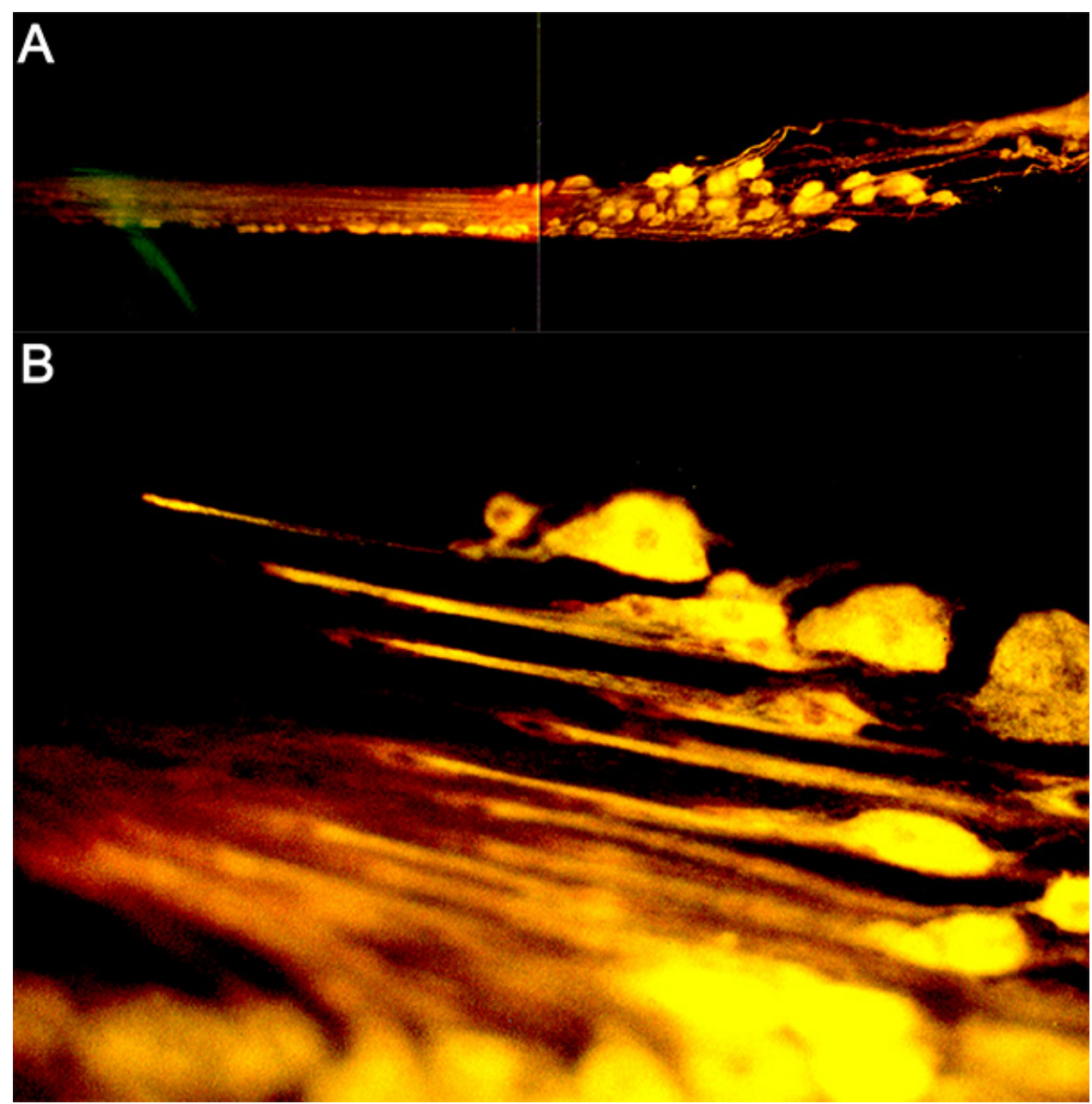

Figure 16. (A) A back-fill of the PD nerve in Cancer magister with 4-Di-2-ASP. (B) Higher magnification of sensory endings. Click here to view larger image.

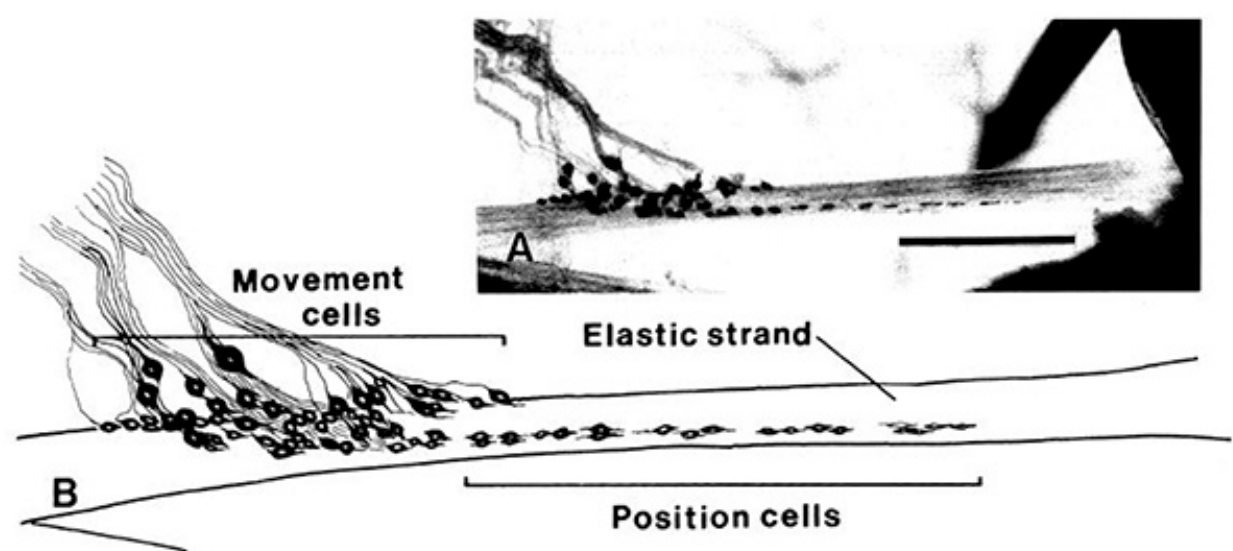

Figure 17. Neurons that were filled with $\mathrm{CoCl}_{2}$ and processed (A). Traced outline of the stained preparation shown (B). Click here to view larger image.

\begin{tabular}{|l|l|}
\hline Saline & g/L \\
\hline $\mathrm{NaCl}$ & 27.29 \\
\hline $\mathrm{KCl}$ & 0.81 \\
\hline $\mathrm{MgSO}_{4} \cdot 7 \mathrm{H}_{2} \mathrm{O}$ & 4.81 \\
\hline $\mathrm{CaCl}_{2} \cdot 2 \mathrm{H}_{2} \mathrm{O}$ & 1.85 \\
\hline
\end{tabular}




\begin{tabular}{|l|l|}
\hline $\mathrm{Na}_{2} \mathrm{SO}_{4} \cdot 10 \mathrm{H}_{2} \mathrm{O}$ & 0.97 \\
\hline Dextrose (D-Glucose) & 1.982 \\
\hline HEPES acid & 0.476 \\
\hline HEPES salt & 2.08 \\
\hline Adjust to pH 8.1 with $\mathrm{NaOH}$ or $\mathrm{HCl}$ & \\
\hline
\end{tabular}

Table 1. Recipes for crab saline.

\section{Discussion}

The purpose of this set of experiments is 1) to teach and exhibit the fundamental principles of extracellular recordings from an identifiable proprioceptive organ and tension nerve and 2) to stress the importance of anatomical mapping in relation to physiological function of particular sensory systems. This experimental approach and the animal models utilized are inexpensive and relatively easy to conduct in neurophysiology teaching laboratories.

The neurons of chordotonal organs are of two specific functional types, those that respond to movement and those responding to static positions. Single cell recordings from a variety of chordotonal organs, no matter which joint is examined, have shown this to be the case ${ }^{3,5}$. Indeed, chordotonal organs associated with the antennal joints of lobsters reveal the same two sensory types and basic anatomy ${ }^{27}$. In addition to there being two neuron types (movement and position), the neurons share the same anatomical arrangement on their respective elastic strands. The large somata located proximally on the strand tend to belong to the dynamic movement sensitive neurons. Neurons that signal static positions have small somata and are located distally. These cells are tonically active. The PD joint only contains a single chordotonal organ while there are two chordotonal organs in the carpus-propodus (CP) and merus-carpus (MC) joints.

The dissection to expose proprioceptive structures in blue crabs (C. sapidus) for electrophysiological recording requires a strategy that allows joint movements to take place in the natural positions while recording from sensory neurons. The tension nerve for the opener muscle in the walking leg is a very fine nerve made up of several neurons. Unless care is taken, the tension nerve as well as the motor nerve innervating the muscle to be stimulated, can be damaged during this dissection. For optimal recordings the suction electrodes need to be tailored to the size of the nerve. Recordings are readily accessible in a student laboratory using a 30-40X magnification dissecting microscope and low-end micromanipulators.

Future experiments that would be interesting to pursue with the joint chordotonal organs would be to examine the structural and physiological profiles during leg regeneration in various species at different stages in the life cycle as a follow up to an initial study that used Cancer magister ${ }^{19,26}$. Questions remaining to be addressed are 1) does the distribution and organization of regenerated neurons depend on the age of the animal when regenerating a limb, 2) are the axonal projections to the CNS (ventral nerve cord) in a regenerating limb functional or does it take time and joint use to establish functional connections, and 3) what happens to the severed axons proximal to the autotomy plane when the limb is autotomized? ${ }^{28}$

Crustaceans conform to environmental conditions and their surrounding temperature, but it is unclear how they maintain coordination within a neural circuit as neurons alter their activity in response to temperature changes. A slow rate of change might allow the animal some time for acclimatization whereas a rapid change may not29,30. Physiological changes in $\mathrm{pH}$ or osmolarity due to metabolism, behavior ${ }^{31}$, or environmental impact may present similar challenges to neural circuits involved in proprioception. These crustacean preparations are ideal for addressing these types of problems because their function is well characterized at a single cell level.

In this protocol we have demonstrated the physiological importance of tension neurons in monitoring force generated by the opener muscle. These tension receptors can be traced to their location within the apodeme by using staining procedures. These neurons, as in mammals, detect force at various levels and recruit additional neurons as the force increases. The frequency in activity is related to the stimulation frequency of the motor neuron until saturation in reception is reached. Using a quick release protocol with the flexed dactylus joint, tension activity quickly disappears but then returns upon regaining tension in a fully extended joint. This is a classic experimental procedure to illustrate the force measured by tension receptors. Various neuromodulators can be applied to the preparation to see how it effects the development of force and neuronal response. One of the important aspects is how the neural responses are processed and integrated in the central nervous system and their impact on activity of motor neurons. The techniques we have shown allow one to start to address more information about the tension (sensory) nerve-motor neuron circuit function, i.e. signal in an intact leg to the ganglion and back to the muscle.

The staining procedures demonstrated are key to understanding the physiology of sensory neurons that innervate proprioceptive organs. Anatomical arrangement of the neurons based on function and the size of the soma are similar in the various chordotonal organs within the crab legs. It is not known if similar neuronal arrangements are also found in other crustacean species or insects. Combining physiological recordings from single cells and mapping the location allows direct structure function relationships. The long term preservation of the anatomical arrangement with $\mathrm{CoCl}_{2}$ staining and fixation allows one to repetitively make measures and assess the structural arrangement.

Proprioception and tension reception of skeletal muscles are sensory modalities that enable coordinated behaviors and responses to external and internal environment for articulated animals in a variety of skeletal muscle configurations. The muscle receptor organ in the abdomen of the crayfish is another well-documented preparation (see the Crawdad Project; http://www.crawdad.cornell.edu/) for teaching purposes of proprioception with only two neurons per abdominal hemi-segment ${ }^{23}$. Being able to record from single neurons to sensory nerve bundles provides further details that aid in understanding the basic principles of sensory reception. These relatively simple crustacean preparations allow one to address fundamental aspects of proprioception and tension monitoring, with the potential to determine the neural circuits that enable central integration of proprioceptive and other sensory inputs ${ }^{9-12,32,33}$. 


\section{Disclosures}

The authors declare that they have no competing financial interests.

\section{Acknowledgements}

The authors are grateful for the artistic contributions of Hyewon Cooper.

\section{References}

1. Whitear, M. Chordotonal organs in Crustacea. Nature. 187, 522-523, doi:10.1038/187522a0 (1960).

2. Alexandrowicz, J.S. The comparative anatomy of leg propriocetors in some decapod Crustacea. J. Mar. Biol. Assoc. U.K. 52 (3), 605-634, doi:http://dx.doi.org/10.1017/S0025315400021615 (1972).

3. Hartman, H.B., Boettiger, E.G. The functional organization of the propys-dactylus organ in Cancer irroratus Say. Comp. Biochem. Physiol. 22, 651-663 (1967).

4. Cooper, R.L., Hartman, H.B. Responses of the bender apodeme tension receptors in the Dungeness crab, Cancer magister. Comp. Biochem. Physiol. A Physiol. 109 (2), 479-486, doi:10.1016/0300-9629(94)90153-8 (1994).

5. Cooper, R.L. Mapping proprioceptive neurons on chordotonal organs in the crab, Cancer magister. Crustaceana. 81 (4), 447-475, http:// dx.doi.org/10.1163/156854008783797499 (2008).

6. Burke, W. An organ for proprioception and vibration sense in Carcinus maenas. J. Exp. Biol. 31, 127-138 (1953).

7. Hill, A. V. First and Last Experiments in Muscle Mechanics. Cambridge University Press, Cambridge, U.K. (1970).

8. Stuart, D.G., Mosher, C.C., Gerlach, R.L., Reinking, R.M. Mechanical arrangement and transducing properties of Golgi tendon organs. Exp. Brain Res. 14 (3), 274-292, doi:10.1007/BF00816163 (1972).

9. Macmillan, D. L. Dando, M.R. Tension receptors on the apodemes of muscles in the walking legs of the crab, Cancer magister. Mar. Behav. Physiol. 1 (1-4), 185-208, doi:10.1080/10236247209386897 (1972).

10. Bévengut, M., Simmers, A.J., Clarac, F. Central neuronal projections and neuromuscular organization of the basal region of the shore crab leg. J. Comp. Neurol. 221 (2), 185-198, doi:http://dx.doi.org/10.1002/cne.902210207 (1983).

11. El Manira, A., Cattaert, D., Clarac, F. Monosynaptic connections mediate resistance reflex in crayfish (Procambarus clarkii) legs. J. Comp. Physiol. A. 168 (3), 337-349, doi:http://dx.doi.org/10.1007/BF00198353 (1991).

12. Le Bon-Jego, M., Cattaert, D. Inhibitory component of the resistance reflex in the locomotor network of the crayfish. J. Neurophysiol. 88 (5), 2575-2588, doi:http://jn.physiology.org/cgi/content/abstract/88/5/2575 (2002).

13. Ray, D.L., Clarac, F., Cattaert, D. Functional analysis of the sensory motor pathway of resistance reflex in crayfish. I. Multisensory coding and motor neuron monosynaptic responses. J. Neurophysiol. 78 (6), 3133-3143, doi:http://jn.physiology.org/cgi/content/abstract/78/6/3133 (1997).

14. Wiersma, C. A. G. Vergleichende Untersuchungenüber das periphere Nerve-muskelsystem von Crustaceen (Comparative studies on the peripheral nerve-muscle system of crustaceans). J. Comp. Physiol. 19, 349-385 (1933).

15. Wiersma, C.A.G. Movement receptors in decapod crustacea. J. Mar. Biol. Assoc. U.K. 38 (01),143-152, doi:http://dx.doi.org/10.1017/ S0025315400015654 (1959).

16. Hartman, H.B. Tension receptors on the closer muscle apodeme in the walking legs of the blue crab Callinectes sapidus. J. Comp. Physiol. A. 157 (3), 355-362 doi:10.1007/BF00618125 (1985).

17. Holsinger, R. The effect of regional phenotypic differences of Procambarus clarkii opener muscle on sarcomere length, fiber diameter, and force development. MSc thesis. University of Kentucky (2013).

18. Parsons, D. W. The morphology and ultrastructure of tension receptors in the walking legs of the crab, Carcinus maenas. Cell Tissue Res. 211 (1), 139-149, doi:10.1007/BF00233729 (1980).

19. Parsons, D. W. Responses and central interactions of tension receptors in the leg muscle of Carcinus. Comp. Biochem. Physiol. A Physiol. 72 (2), 391-399, doi:http://dx.doi.org/10.1016/0300-9629(82)90236-5 (1982).

20. Tryba, A.K., Hartman, H.B. Dynamic responses of series force receptors innervating the opener muscle apodeme in the blue crab, Callinectes sapidus. J. Comp. Physiol. A. 180 (3), 215-221, doi:10.1007/s003590050042 (1997).

21. Whitear, M. The fine structure of crustacean proprioceptors. I. The chordotonal organs in the legs of the shore crab, Carcinus meanas. Philos. Trans. R. Soc. Lond. B Biol. Sci. 245 (725), 291-325 (1962).

22. Whitear, M. The fine structure of crustacean proprioceptors. II. The thoracico-coxal organs in Carcinus, Pagurus and Astacus. Philos. Trans. R. Soc. Lond. B Biol. Sci. 248 (752), 437-456 (1965).

23. Leksrisawat, B., Cooper, A. S., Gilberts, A. B., Cooper, R. L. Muscle Receptor Organs in the Crayfish Abdomen: A Student Laboratory Exercise in Proprioception. J. Vis. Exp. (45), e2323, doi:10.3791/2323 (2010).

24. Baierlein, B., Thurow, A. L., Atwood, H. L., Cooper, R. L. Membrane Potentials, Synaptic Responses, Neuronal Circuitry, Neuromodulation and Muscle Histology Using the Crayfish: Student Laboratory Exercises. J. Vis. Exp. (47), e2322, doi:10.3791/2322 (2011).

25. Delaney K, and Gelperin, A. Cerebral interneurons controlling fictive feeding in Limaxmaximus; I. Anatomy and criteria for re-identification. J. Comp. Physiol. A. 166, 297-310 (1990).

26. Hartman, H.B. \& Cooper, R.L. Regeneration and molting effects on a proprioceptor organ in the Dungeness crab, Cancer magister. J. Neurobiol. 25 (5), 461-471 (1994).

27. Hartman, H.B., Austin, W.D. Proprioceptor organs in the antennae of Decapoda Crustacea. J. Comp. Physiol. 81 (2), 187-202, doi:10.1007/ BF00696632 (1972).

28. Cooper, R.L. Development of sensory processes during limb regeneration in adult crayfish. J. Exp. Biol. 201 (Pt 11), 1745\#1752 (1998).

29. Chung,Y-S. Cooper, R.M., Graff, J., Cooper, R.L. The acute and chronic effect of low temperature on survival, heart rate and neural function in crayfish (Procambarus clarkii) and prawn (Macrobrachium rosenbergii) species. Open J. Mol. Int. Physiol. 2 (3), 75-86, doi:10.4236/ ojmip.2012.23011 (2012). 
30. Blundon, J. A. Effects of temperature and thermal history on neuromuscular properties of two crustacean species. J. Comp. Physiol. B. 158 (6), 689-696, doi:10.1007/BF00693006 (1989).

31. Cooper, R.M., Schapker, H., Adami, H., \& Cooper, R.L. Heart and ventilatory measures in crayfish during copulation. Open J. Mol. Int. Physiol. 1 (3), 36-42, doi:10.4236/ojmip.2011.13006 (2011).

32. Bierbower, S.M., Cooper, R.L. The mechanistic action of carbon dioxide on a neural circuit and NMJ communication. Journal of Experimental Zoology. doi: 10.1002/jez.1798 (2013).

33. Bierbower, S.M., Shuranova, Z. P., Viele, K.,Cooper, R.L. Sensory systems and environmental change on behavior during social interactions. Brain Behav. 3 (1), 4 - 13 (2013). 